\title{
Shaking Table Tests on the Seismic Response of a Columnless Subway Station with Asymmetric Load under Bidirectional Seismic Action
}

\author{
Jiangle $\mathrm{Li}^{1 *}$, Shirong Zhang ${ }^{1,2}$, Sheliang Wang ${ }^{1}$, Zhonghua Liu ${ }^{1}$, Yanzhou Hao ${ }^{1}$ \\ ${ }^{1}$ Xi' an University of Architecture and Technology, Xi'an 7100552, China \\ ${ }^{2}$ Nanning Rail Transit Co., Ltd., Nanning 530029, China
}

Corresponding Author Email: 30080206@hncj.edu.cn

https://doi.org/10.18280/ijsse.100416

Received: 27 March 2020

Accepted: 6 June 2020

\section{Keywords:}

bidirectional earthquake, unidirectional earthquake, shaking table test, time history, asymmetric slope, vertical seismic wave

\begin{abstract}
Drawing on the theory of model similarity, the failure mode of a columnfree long-span subway station under asymmetric load was discussed under seismic waves, in the light of different frequency spectrum features, loading conditions, and ground motion intensities. Specifically, a largescale model was designed for the subway station, and subjected to shaking table tests. Based on the test data, the authors comparatively analyzed the seismic responses of the model under unidirectional and bidirectional earthquakes. The results show that: (1) The acceleration response of the model increased with the acceleration amplitude. The dynamic response of the model is more complex and greater under bidirectional earthquake than under unidirectional earthquake. (2) The middle plate is the weak link in seismic design, and should therefore be enhanced. (3) The acceleration response was larger when the model had an asymmetric slope, for the dynamic response is amplified by the asymmetric load. Hence, the asymmetric slope suppresses the seismic resistance of the model. (4) The strains of the model gradually increased with the growing amplitude of ground motion; The middle plate had a greater strain than other plates, indicating that this plate has relatively low stiffness, and deforms significantly under seismic action. (5) The earth pressure values under bidirectional seismic action were greater than the simple superposition between the values under horizontal seismic action and the vertical seismic action. The research results provide a good reference for the seismic design of underground structures.
\end{abstract}

\section{INTRODUCTION}

The earthquake could bring serious damages to the inflicted area, including direct consequence like building collapse and secondary disasters like sand gushing, landslide, debris flow and ground subsidence. Traditionally, it is believed that underground structures suffer from fewer damages than ground structures during an earthquake. But many seismic evidences [1, 2] suggest otherwise: seismic damages of underground structures are reported frequently. Taking the Great Hanshin Earthquake for example, the most serious damages occurred underground. During the earthquake, many underground structures were impaired, ranging from railways, parking lots, tunnels, to commercial streets. Five subway stations underwent severe destruction, especially the Dakai station [3]. More than half of the central columns at the station completely collapsed, causing the roof to fall and the overlying soil to settle by a maximum of $2.5 \mathrm{~m}$.

Of course, underground structures still have much better seismic resistance than ground structures, provided that the surrounding rock is rigid, the earthquake is of low magnitude, and the buried depth is suitable [4]. The traditional view holds that structural damage mainly depends on the horizontal seismic force, but has little to do with the vertical seismic force [5]. In 2008 Sichuan Earthquake, however, the horizontal and vertical seismic components seemed to have the same intensity, resulting in high seismic damages to many tunnels and underground engineering facilities [6].

Many scholars have explored the seismic effect on underground structures. Based on the ANSYS finite-element software, Zhuang et al. [7] created a nonlinear viscoelastic model of the dynamic soil features under cyclic load, numerically simulated the seismic damage mechanism of Dakai station in the Great Hanshin Earthquake, and summarized the damage evolution at the station: the collapse of the station is mainly resulted from the failures of the roof and central columns. Through shaking table tests, Tamari and Towhata [8] detailed the soil-structure interaction in underground engineering, and established the relationship between soil-structure stress/strain, effective pore pressure, and earth pressure. Wang et al. [9] considered the portal section as the most vulnerable part of underground structures during earthquakes, pointing out that the portal section and portal slope are the most dangerous parts of a tunnel under seismic action, in addition to the high-intensity seismic area and the active fault zone. Dowding and Rozan [10] suggested that, in a tunnel structure under asymmetric load, the free side of the lateral slope at the portal section in a tunnel is prone to collapse and instability, due to the weak overburden and broken rock mass.

The shaking table test has often been adopted to study the seismic response of underground structures. For instance, Jiang et al. [11, 12] carried out a series of shaking table tests to identify the seismic behaviors of a small shallow tunnel 
under asymmetric load, and concluded that the peak seismic wave has much greater impact on the acceleration response of tunnel than the type of seismic wave. Liu et al. [13] observed that the corresponding measuring points on the two sides of the target tunnel differed in acceleration and strain, under different seismic waves. Lei et al. [14] obtained the failure modes and velocity fields of shallow tunnels under asymmetric load, and found that the method specified in the current code underestimates the effect of asymmetric load of surrounding rock pressure on shallow tunnels. Li et al. [15] discovered that the asymmetric load of ground surface only affects the acceleration of the surrounding rock within a limited depth, and the free surface of a tunnel under asymmetric load tends to displace more than that of a tunnel under symmetric load. Overall, many shaking table tests have been performed on tunnels under symmetric load [16-21], but few have been conducted on tunnels under asymmetric load.

To the best of our knowledge, there is no research of columnless subway station through shaking table test, under the conditions of bidirectional earthquake and asymmetric load. This paper introduces shaking table test to examine the dynamic response law of a subway station under asymmetric load. Different frequency spectra, loading modes, and seismic intensities were considered in the testing process. The research results provide a good reference for the seismic design of subway stations under asymmetric load.

\section{SHAKING TABLE TESTS}

\subsection{Model design}

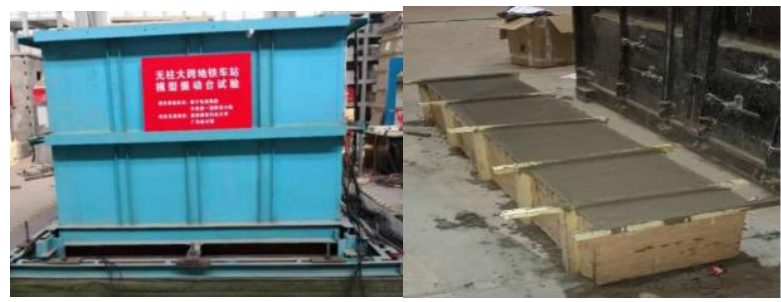

(a) Exterior of model box (b) Model maintenance

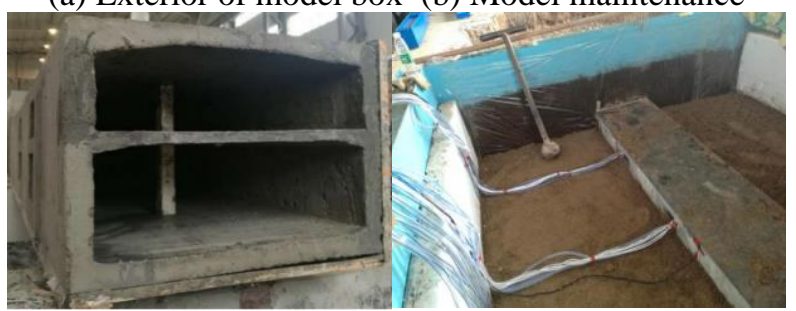

(c) Model of subway station (d) Model embedding

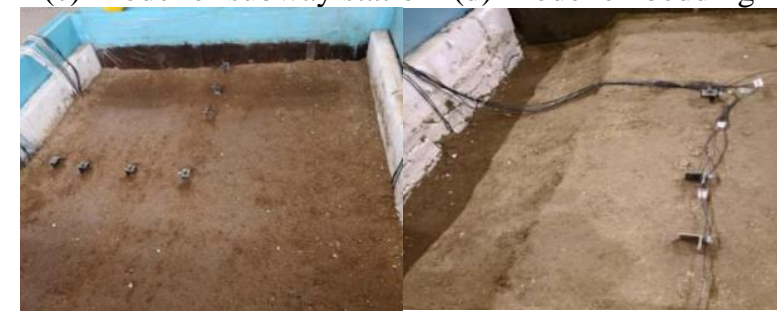

(e)pressure balancing system (f) eccentric compression system

Figure 1. The model box and test setup

As shown in Figure 1(a), the model box is made of steel frame and steel plate. The model box is $2.15 \mathrm{~m}$ long and $1.2 \mathrm{~m}$ tall along the vibration direction, and $2.35 \mathrm{~m}$ long and $1.2 \mathrm{~m}$ tall perpendicular to the vibration direction. Gravels were placed at the bottom of the box to increase the friction between the soil and the bottom. To eliminate the boundary effect, $10 \mathrm{~cm}$ thick polystyrene foam boards were pasted on the two box walls parallel to the vibration direction. In addition, preservative films and lubricating oil were applied on the two walls perpendicular to the vibration direction, with the aim to reduce the friction of these walls.

As shown in Figures 1(b) and (c), the model structure mainly consists of particulate concrete and galvanized steel wire mesh. The mix ratio of the particulate concrete is $425 \#$ cement: coarse sand: lime: water $=1: 5: 0.34: 0.8$. Figures $1(\mathrm{~d})$ and (e) illustrate the embedding of the model, and the deployment of internal measuring points, respectively. Finally, a slope was created (Figure 1(f)) to simulate the asymmetric load.

The shaking table tests were carried out in the Key Lab of Structure and Earthquake Resistance, Xi'an University of Architecture and Technology. Three seismic waves were adopted for the tests, including two natural waves (i.e. El Centro wave and Wenchuan wave) and an artificial wave (Ren wave). The seismic response spectra are compared with design response spectra in Figure 2; the time history of accelerations of the ground motion are recorded in Figure 3.

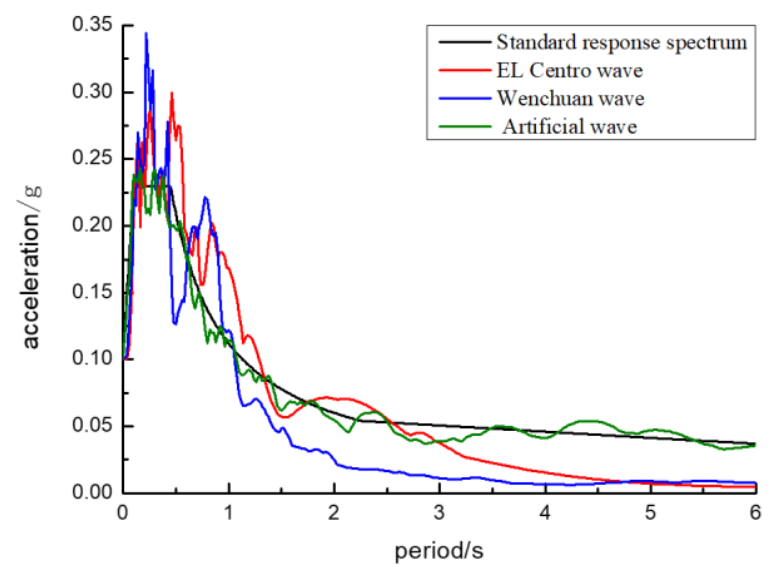

Figure 2. The comparison between seismic response spectra and design response spectra
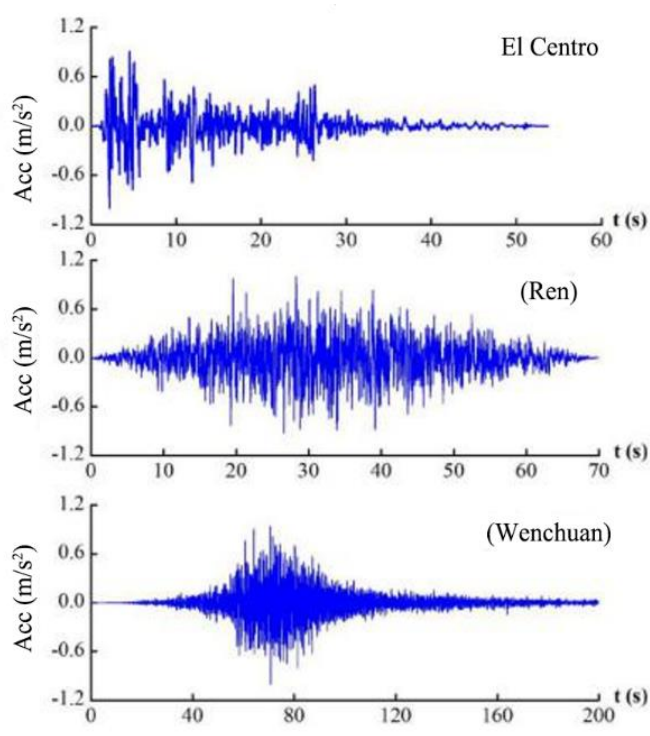

Figure 3. The time history of accelerations of the ground motion 


\subsection{Similarity ratio}

According to the theory on model similarity and the basic parameters of the shaking table, the similarity ratio of the test model was selected as 1: 50; the geometric dimension, density $\rho$, and elastic modulus $\mathrm{E}$ were taken as the basic physical quantities. The similarity relationship and the similarity of physical quantities of the model are shown in Table 1.

\subsection{Soil material}

The elastic moduli of upper soil and lower soil were set to 3.72Mpa and $8.41 \mathrm{Mpa}$, respectively. The cohesion and internal friction angle of the soil were measured by direct shear test. The test results are shown in Table 2.

Table 1. The similarity relationship and the similarity of physical quantities of the model

\begin{tabular}{ccccc}
\hline Physical parameter & Symbol of similarity ratio & Similarity & Structure model & Ground model \\
\hline length & $\mathrm{S} l$ & $\mathrm{~S} 1$ & $1 / 50$ & $1 / 50$ \\
area & $\mathrm{S}_{\mathrm{A}}$ & $\mathrm{S}_{\mathrm{A}}=\mathrm{S} 1^{\wedge} 2$ & $1 / 2500$ & $1 / 2500$ \\
Linear displacement & $\mathrm{Sx}$ & $\mathrm{Sx}=\mathrm{S} 1$ & $1 / 50$ & $1 / 50$ \\
Elastic Modulus & $\mathrm{SE}$ & $/$ & $13 / 63$ & Actual measurement \\
strain & $\mathrm{S} \varepsilon$ & $\mathrm{S} \varepsilon=[1]$ & 1 & 1 \\
stress & $\mathrm{S} \sigma$ & $\mathrm{S} \sigma=\mathrm{SE}$ & $13 / 63$ & $/$ \\
Model equivalent density & $\mathrm{S} \rho$ & $/$ & 2.130 & $/$ \\
time & $\mathrm{St}$ & $\mathrm{St}=\mathrm{S} 1(\mathrm{~S} \rho / \mathrm{SE})^{\wedge} 0.5$ & 0.064 & \\
frequency & $\mathrm{S} \omega$ & $\mathrm{S} \omega=1 / \mathrm{St}$ & 15.563 & \\
\hline
\end{tabular}

Table 2. The cohesion and internal friction angle of the soil

\begin{tabular}{cccccc}
\hline Material & Density $\left(\mathbf{k g} / \mathbf{m}^{\mathbf{3}}\right)$ & Elastic modulus $(\mathbf{M P a})$ & Poisson ratio & Cohesion coefficient $(\mathbf{k P a})$ & Internal friction angle $\left(^{\circ}\right)$ \\
\hline Upper soil & 1497 & 3.72 & 0.3 & 14.12 & 32.1 \\
Lower soil & 1649 & 8.41 & 0.3 & 26.63 & 28.5 \\
Micro concrete & 2005 & 6635 & 0.3 & $/$ & $/$ \\
\hline
\end{tabular}

\subsection{Test plan}

As shown in Figure 4, the shaking table tests adopt a total of 49 acceleration sensors, 30 strain gauges, and 14 earth pressure gauges. The layout of these measuring points is explained in Figure 5. The middle section of the model is the main measuring surface. The measuring points AP11, AP12, and AP13 are respectively deployed at the middle of the top plate, the middle plate, and the lower plate of the subway model.

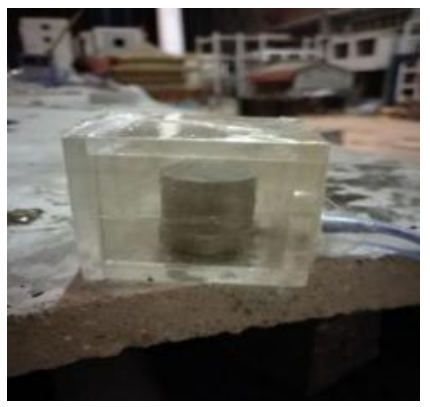

(a) Accelerometers

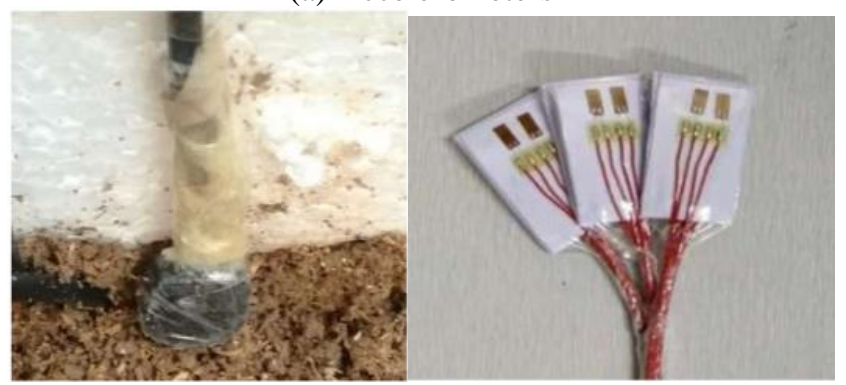

(b) Earth pressure gauges (c) Strain gauges

Figure 4. The sensors used in shaking table tests

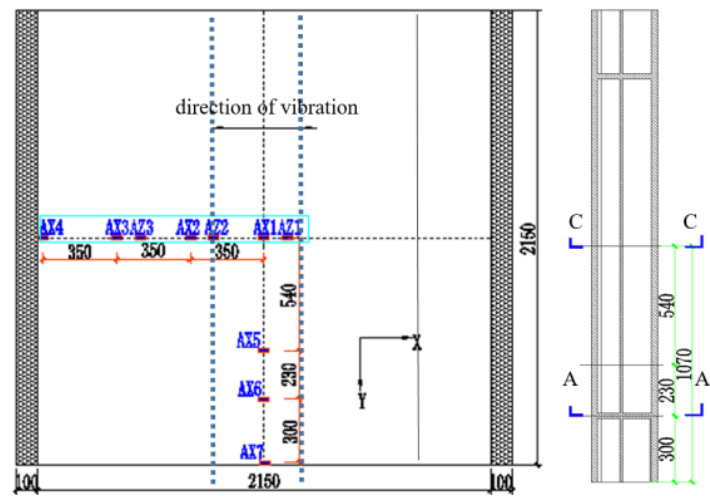

(a) Top plate

(b) Left side

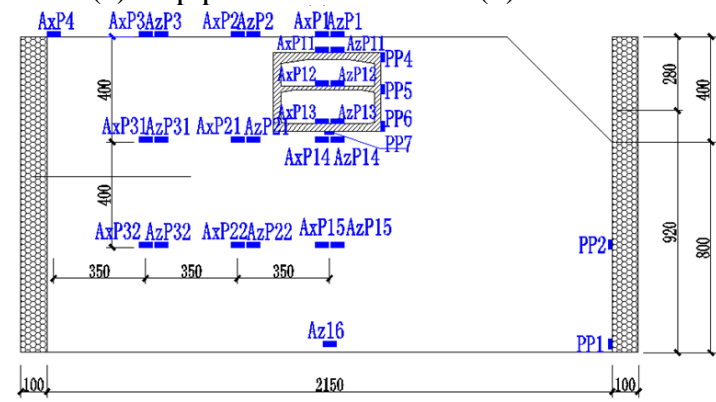

(c) Front view of the main measuring plane

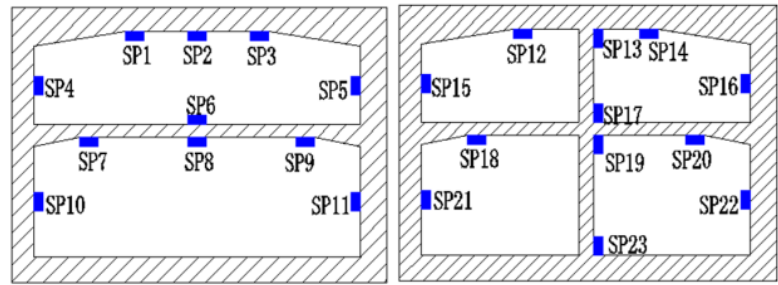

(d) Layout of strain gauges at Section C-C

(e) Layout of strain gauges at Section A-A

Figure 5. The layout of measuring points 


\subsection{Ground motion parameters}

For the target subway station, the fortification intensity is 7 , the design acceleration is $0.10 \mathrm{~g}$, the design earthquake group is the first group, and the site class is Class III. According to site survey and design report, the peak acceleration of the ground motion was adjusted according to that of a Class II site with an adjustment coefficient of 1.25. Therefore, the basic acceleration of the site was set to $0.125 \mathrm{~g}$. The features of ground motion are summarized in Table 3. The loading conditions of the tests are given in Table 4.

Table 3. The summary of ground motion features

\begin{tabular}{|c|c|c|c|c|c|c|}
\hline Seismic wave & $\begin{array}{c}\text { Peak } \\
\text { acceleration }(\mathrm{g})\end{array}$ & $\begin{array}{c}\text { Time of peak } \\
\text { acceleration (s) }\end{array}$ & Hold time (s) & Effective duration (s) & $\begin{array}{c}\text { Equivalent shear wave } \\
\text { velocity VS30 }(\mathrm{m} / \mathrm{s})\end{array}$ & $\begin{array}{c}\text { Time } \\
\text { interval (s) }\end{array}$ \\
\hline EL Centro-180 & 0.281 & 2.17 & 53.72 & 24.20 & 213.44 & 0.01 \\
\hline Wenchuan & 0.164 & 70.89 & 199.6 & 128.395 & Three types of venues & 0.005 \\
\hline Artificial wave (Ren) & 0.100 & 28.26 & 70.00 & 62.02 & Artificially generated & 0.01 \\
\hline
\end{tabular}

Table 4. The loading conditions of the tests

\begin{tabular}{|c|c|c|c|c|c|c|c|}
\hline \multirow{2}{*}{ Condition } & \multirow{2}{*}{ Seismic wave } & \multicolumn{2}{|c|}{ Model structure (g) } & \multirow{2}{*}{ Condition } & \multirow{2}{*}{ Seismic wave } & \multicolumn{2}{|c|}{ Model structure (g) } \\
\hline & & $\mathbf{X}$ & $\mathbf{Z}$ & & & $\mathbf{X}$ & $\mathbf{Z}$ \\
\hline \multirow{3}{*}{1} & Artificial wave & 0.968 & - & 6 & Artificial wave & 0.867 & 0.433 \\
\hline & EL Centro wave & 0.968 & - & & EL Centro wave & 0.867 & 0.433 \\
\hline & Wenchuan wave & 0.968 & - & & Wenchuan wave & 0.867 & 0.433 \\
\hline \multirow{3}{*}{2} & Artificial wave & - & 0.968 & 7 & Artificial wave & 0.684 & 0.684 \\
\hline & EL Centro wave & - & 0.968 & & EL Centro wave & 0.684 & 0.684 \\
\hline & Wenchuan wave & - & 0.968 & & Wenchuan wave & 0.684 & 0.684 \\
\hline \multirow{3}{*}{3} & Artificial wave & 0.968 & 0.484 & 8 & Artificial wave & 0.433 & 0.867 \\
\hline & EL Centro wave & 0.968 & 0.484 & & EL Centro wave & 0.433 & 0.867 \\
\hline & Wenchuan wave & 0.968 & 0.484 & & Wenchuan wave & 0.433 & 0.867 \\
\hline \multirow{3}{*}{4} & Artificial wave & 1.200 & - & 9 & Artificial wave & 0.968 & Symmetric slope \\
\hline & EL Centro wave & 1.200 & - & & EL Centro wave & 0.968 & Symmetric slope \\
\hline & Wenchuan wave & 1.200 & - & & Wenchuan wave & 0.968 & Symmetric slope \\
\hline \multirow{3}{*}{ 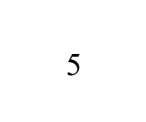 } & Artificial wave & 1.200 & 0.600 & & & & \\
\hline & EL Centro wave & 1.200 & 0.600 & & & & \\
\hline & Wenchuan wave & 1.200 & 0.600 & & & & \\
\hline
\end{tabular}

\section{DYNAMIC RESPONSE ANALYSIS}

\subsection{Differences in seismic response under unidirectional and bidirectional earthquakes}

During the shaking table tests, acceleration sensors AP11, AP12, and AP13 were respectively arranged on the bottom, middle, and top plates to capture the acceleration response of the model with asymmetric load under seismic action. Figure 6 shows the time history of the acceleration response at AP11 under three different seismic waves.

As shown in Figure 6, under different seismic waves, the acceleration responses at the measuring point of AP11 were like the input ground motion; the strong earthquakes lasted for basically the same duration; the peak acceleration exhibited a certain law. With the increase of acceleration amplitude, the acceleration response at the measuring point gradually climbed up.

The comparisons between conditions 1-3 and 4-5 indicate that the dynamic response of the model was more complex and greater under bidirectional earthquake than under unidirectional earthquake. The opposite was observed under El Centro wave: the dynamic response of the model was larger under unidirectional earthquake, probably a result of the spectral features of the wave.

3.2 Differences in seismic response between models with asymmetric and symmetric slopes
Figure 7 shows the time history of the acceleration response at AP11 of the model with a symmetric slope with that of the model with an asymmetric slope under condition 1 .

Obviously, the acceleration response at the measuring point was larger when the model had an asymmetric slope. The possible reason is that the dynamic response is amplified due to the lack of soil on the right side of the model with asymmetric slope. Hence, the asymmetric slope suppresses the seismic resistance of the model.

\subsection{Differences in seismic response between different plates}

To disclose the variation in ground motion amplitude with different plates in the model, the acceleration responses were measured at AP11, AP12, AP13 under different seismic waves incident in the horizontal direction under condition 1 , and then measured under different seismic waves incident in the vertical direction under condition 2. The time history of the acceleration responses at these points are recorded in Figure 8.

As shown in Figure 8(a), when the three kinds of seismic waves were applied in the horizontal direction, the three plates can be ranked as top plate $>$ middle plate $>$ bottom plate, in descending order of the peak acceleration response; in this case, the structural response increased with the amplitude of input seismic wave.

As shown in Figure 8(b), when the three kinds of seismic waves were applied in the vertical direction, the three plates can be ranked as middle plate $>$ top plate $>$ bottom plate, in 
descending order of the peak acceleration response; the middle plate is greatly affected by the vertical seismic waves, making it the weak link in seismic design. As a result, the middle plate must be strengthened to improve the seismic performance of the entire model.
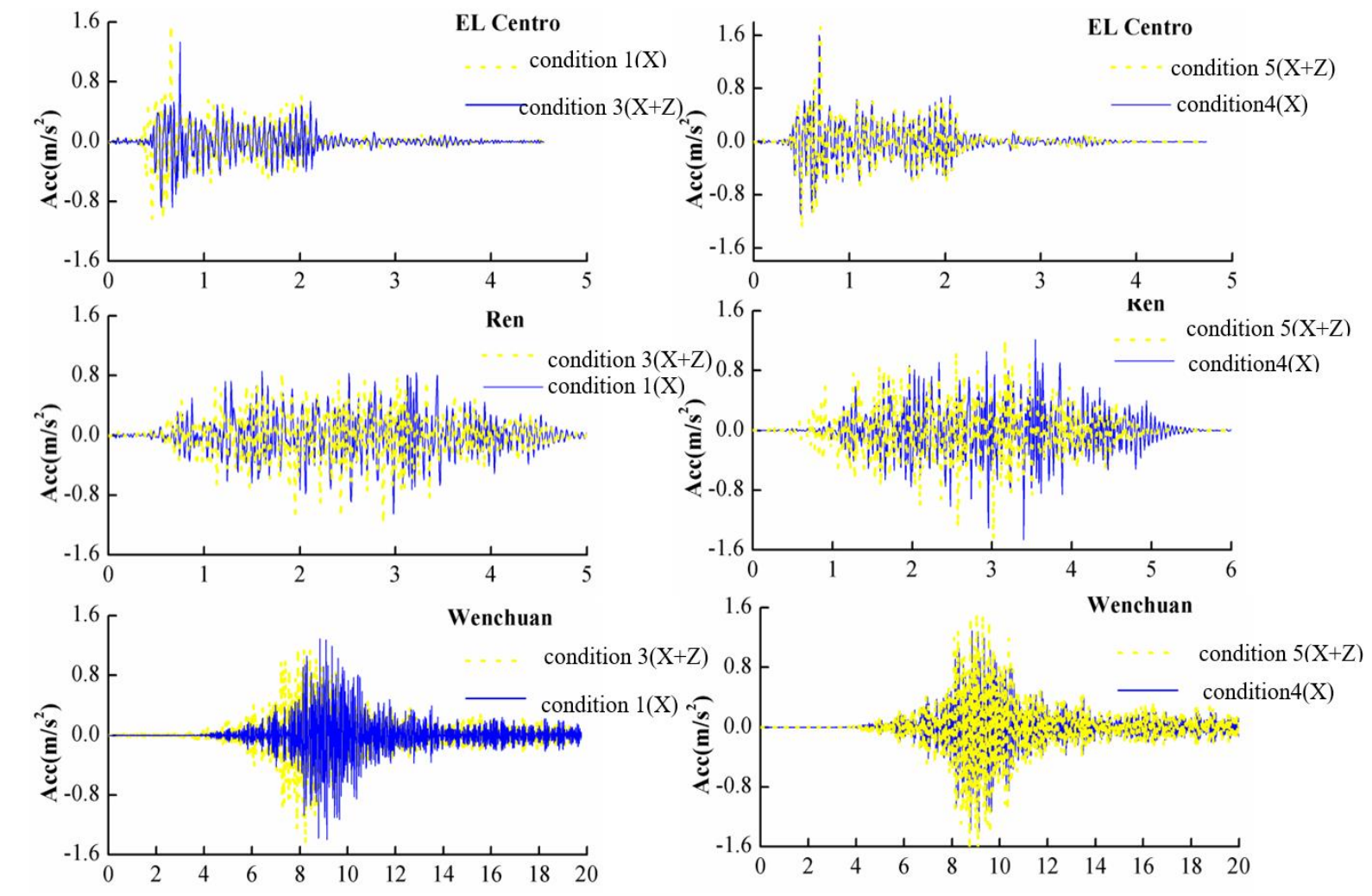

Figure 6. The time-history of acceleration responses at AP11 under unidirectional and bidirectional earthquakes
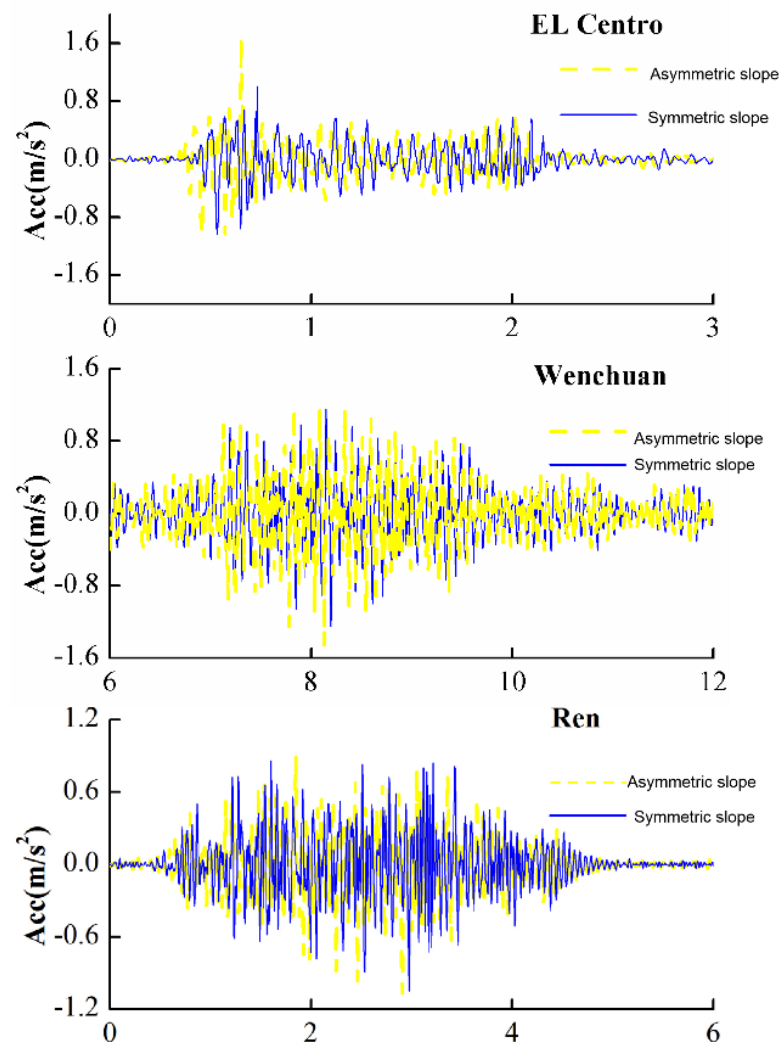

Figure 7. The time history of the acceleration response at AP11 of the model with a symmetric slope and that of the model with an asymmetric slope under condition 1 


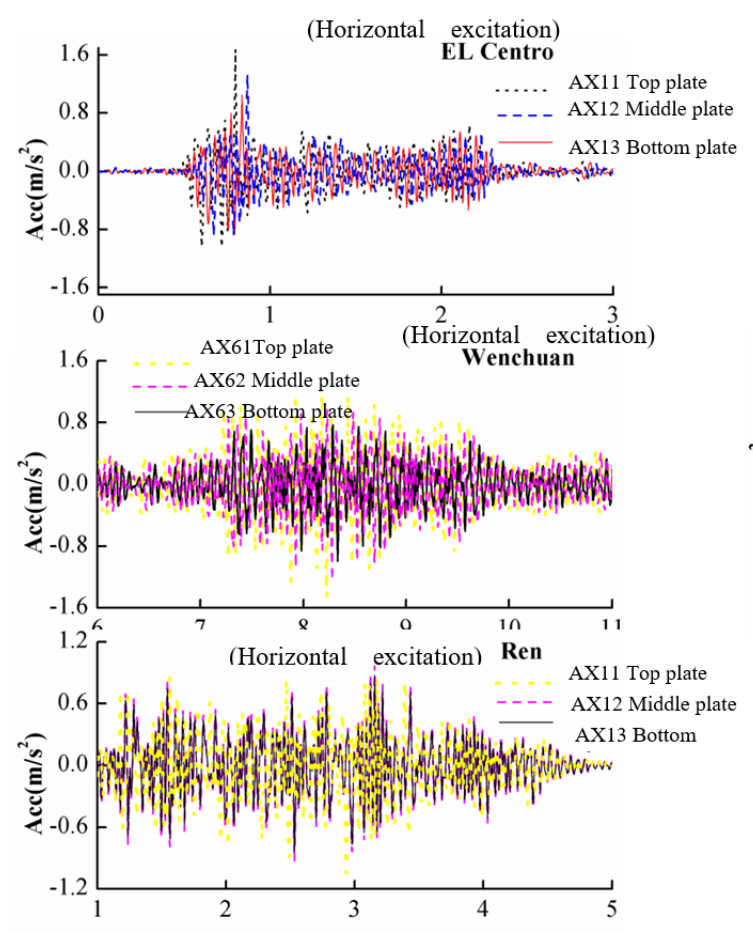

(a)

(a) Condition 1
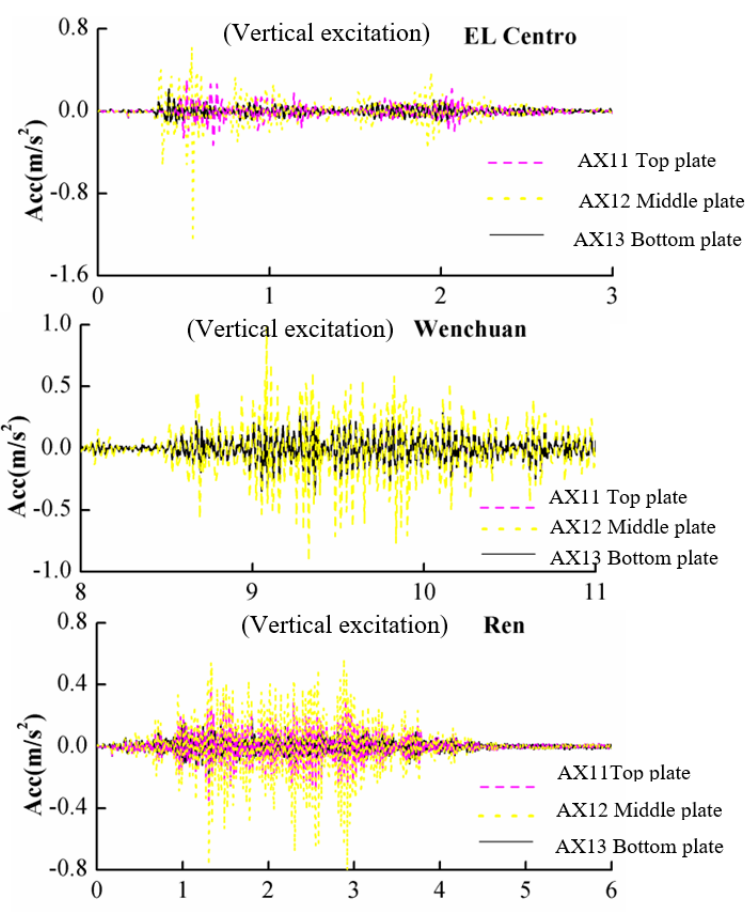

(b)

(b) Condition 2

Figure 8. The time history of the acceleration responses at AP11, AP12, and AP13 under horizontal and vertical seismic waves

\subsection{Differences in structural strain under unidirectional and bidirectional earthquakes}

Taking the El Centro wave as an example, the strain amplitudes of the different plates of model under various conditions are shown in Table 5.

It can be seen that, the strain of the model increased gradually with the growing amplitude of the ground motion; the middle plate had a greater strain than other plates; the strains collected under vertical seismic action were smaller than those collected under horizontal seismic action; the end surface had smaller strains than the main observation surface. Then, it is inferred that the middle plate has relatively low stiffness, and deforms significantly under seismic action.

\subsection{Differences in the dynamic earth pressure between the model with asymmetrical slope and that with symmetrical slope}

To clarify the soil-structure interaction, miniature soil pressure boxes were placed between the soil and the model. Then, the dynamic pressure between the soil and the model were measured through the shaking table tests. Under the El Centro wave, the earth pressures on the side walls and bottom plate of the model are recorded in Table 6 .

As shown in Table 6, the model had higher earth pressures under bidirectional seismic action than under unidirectional seismic action. Moreover, the earth pressure values under bidirectional seismic action were greater than the simple superposition between the values under horizontal seismic action and the vertical seismic action. This means the dynamic response is a coupled action under bidirectional earthquake. In addition, the dynamic earth pressure at PP4 was greater than that at PP6, indicating that, under seismic action, the top of the model is squeezed more significantly by the soil than the bottom. This is mainly because the slope on the right side of the model makes the structure asymmetric. The phenomenon echoes with the strain change law observed in the subway station.

Table 5. The strain amplitudes of different plates under El Centro wave (unit: $\mu \varepsilon$ )

\begin{tabular}{|c|c|c|c|c|c|c|c|c|c|c|c|c|c|}
\hline \multicolumn{2}{|c|}{ Condition } & C1 & $\mathrm{C} 2$ & C3 & $\mathrm{C4}$ & C5 & \multicolumn{2}{|c|}{ Condition } & C1 & C2 & $\mathrm{C3}$ & $\mathrm{C4}$ & $\mathrm{C5}$ \\
\hline \multirow{6}{*}{ Left wall } & SP4 & 100 & 53 & 173 & 120 & 207 & \multirow{6}{*}{ Top plate } & SP1 & 43 & 37 & 50 & 52 & 59 \\
\hline & SP15 & 85 & 45 & 147 & 102 & 176 & & SP12 & 40 & 35 & 47 & 48 & 54 \\
\hline & SP10 & 130 & 69 & 225 & 156 & 270 & & SP2 & 50 & 44 & 48 & 60 & 68 \\
\hline & SP21 & 111 & 59 & 192 & 133 & 230 & & SP13 & 46 & 40 & 43 & 55 & 62 \\
\hline & & & & & & & & SP3 & 44 & 38 & 53 & 53 & 60 \\
\hline & & & & & & & & SP14 & 41 & 36 & 48 & 49 & 55 \\
\hline \multirow{6}{*}{$\begin{array}{l}\text { Right } \\
\text { wall }\end{array}$} & SP5 & 85 & 45 & 147 & 102 & 176 & \multirow{6}{*}{$\begin{array}{c}\text { Middle } \\
\text { plate }\end{array}$} & SP7 & 47 & 41 & 54 & 56 & 63 \\
\hline & SP16 & 72 & 38 & 124 & 86 & 149 & & SP18 & 40 & 35 & 47 & 48 & 54 \\
\hline & SP11 & 76 & 40 & 131 & 91 & 158 & & SP8 & 52 & 45 & 60 & 62 & 70 \\
\hline & SP22 & 65 & 34 & 112 & 78 & 135 & & SP19 & 44 & 38 & 54 & 53 & 60 \\
\hline & & & & & & & & S9P & 43 & 37 & 55 & 52 & 59 \\
\hline & & & & & & & & SP20 & 37 & 32 & 48 & 44 & 50 \\
\hline
\end{tabular}


Table 6. Dynamic earth pressure under El-Centro wave action

\begin{tabular}{ccccccccc}
\hline \multirow{2}{*}{ Condition } & \multicolumn{8}{c}{ Soil pressure (kPa) } \\
\cline { 2 - 9 } & PP4 & PP5 & PP6 & PP7 & PP8 & PP9 & PP10 & PP11 \\
\hline 1 & 2.131 & 1.231 & 0.891 & 1.461 & 1.769 & 1.022 & 0.740 & 1.213 \\
2 & 1.321 & 0.763 & 0.552 & 1.906 & 1.096 & 0.633 & 0.458 & 1.582 \\
3 & 3.832 & 2.213 & 1.602 & 2.737 & 3.181 & 1.837 & 1.330 & 2.272 \\
4 & 2.557 & 1.477 & 1.069 & 1.753 & 2.122 & 1.226 & 0.887 & 1.455 \\
5 & 4.598 & 2.656 & 1.922 & 3.152 & 3.816 & 2.204 & 1.595 & 2.616 \\
\hline
\end{tabular}

\section{CONCLUSIONS}

This paper designs a largescale model of a columnfree longspan subway station, and carries out shaking table tests to study the seismic responses of the model under unidirectional and bidirectional earthquakes. The main conclusions are as follows:

(1) The acceleration response of the model increased with the acceleration amplitude. The dynamic response of the model is more complex and greater under bidirectional earthquake than under unidirectional earthquake

(2) When the three kinds of seismic waves were applied in the horizontal direction, the three plates can be ranked as top plate $>$ middle plate $>$ bottom plate, in descending order of the peak acceleration response; when the three kinds of seismic waves were applied in the vertical direction, the three plates can be ranked as middle plate $>$ top plate $>$ bottom plate, in descending order of the peak acceleration response; therefore, the middle plate is the weak link in seismic design.

(3) The acceleration response was larger when the model had an asymmetric slope. The possible reason is that the dynamic response is amplified by the asymmetric load. Hence, the asymmetric slope suppresses the seismic resistance of the model.

(4) The middle plate had a greater strain than other plates; the strains of the model gradually increased with the growing amplitude of ground motion; the middle plate has relatively low stiffness, and deforms significantly under seismic action.

(5) The dynamic response of the model is a coupled action under bidirectional earthquake: the earth pressure values under bidirectional seismic action were greater than the simple superposition between the values under horizontal seismic action and the vertical seismic action.

\section{ACKNOWLEDGMENT}

This work is supported by National Natural Science Foundation of China Youth Fund Project (Grant No.: 516784802), Nanning Rail Transit Co., Ltd research project (2019).

\section{REFERENCES}

[1] Dowding, C.H., Rozan, A. (1978). Damage to rock tunnels from earthquake shaking. Journal of Geotechnical Engineering Division, 104(2): 175-191.

[2] Liu, H., Song, E. (2005). Seismic response of large underground structures in liquefiable soils subjected to horizontal and vertical earthquake excitations. Computers and Geotechnics, 32(4): 223-244. https://doi.org/10.1016/j.compgeo.2005.02.002
[3] Nakamura, S., Yoshida, N., Iwatate, T. (1996). Damage to Daikai subway station during the 1995 HyogokenNambu earthquake and its investigation. Japan Society of Civil Engineers, Committee of Earthquake Engineering, 6: 287-295.

[4] He, C., Koizumi, A. (2001). Study on seismic behavior and seismic design methods in transverse direction of shield tunnels. Structural Engineering and Mechanics, 11(6): 651-662. https://doi.org/10.12989/sem.2001.11.6.651

[5] Hashash, Y.M., Hook, J.J., Schmidt, B., John, I., Yao, C. (2001). Seismic design and analysis of underground structures. Tunnelling and Underground Space Technology, 16(4): 247-293. https://doi.org/10.1016/S0886-7798(01)00051-7

[6] Wang, Z.Z., Zhang, Z. (2013). Seismic damage classification and risk assessment of mountain tunnels with a validation for the 2008 Wenchuan earthquake. Soil Dynamics and Earthquake Engineering, 45: 45-55. https://doi.org/10.1016/j.soildyn.2012.11.002

[7] Zhuang, H., Chen, G., Hu, Z., Qi, C. (2016). Influence of soil liquefaction on the seismic response of a subway station in model tests. Bulletin of Engineering Geology and the Environment, 75(3): 1169-1182. https://doi.org/10.1007/s10064-015-0777-y

[8] Tamari, Y., Towhata, I. (2003). Seismic soil-structure interaction of cross sections of flexible underground structures subjected to soil liquefaction. Soils and Foundations, 43(2): https://doi.org/10.3208/sandf.43.2_69

[9] Wang, W.L., Wang, T.T., Su, J.J., Lin, C.H., Seng, C.R., Huang, T.H. (2001). Assessment of damage in mountain tunnels due to the Taiwan Chi-Chi earthquake. Tunnelling and Underground Space Technology, 16(3): 133-150. https://doi.org/10.1016/s0886-7798(01)000475

[10] Dowding, C.H., Rozan, A. (1978). Damage to rock tunnels from earthquake shaking. Journal of the Geotechnical Engineering Division, 104(2): 175-191. https://cedb.asce.org/CEDBsearch/record.jsp?dockey $=0$ 007873

[11] Jiang, X., Wang, F., Yang, H., Sun, G., Niu, J. (2018). Dynamic response of shallow-buried small spacing tunnel with asymmetrical pressure: Shaking table testing and numerical simulation. Geotechnical and Geological Engineering, 36(4): 2037-2055. https://doi.org/10.1007/s10706-017-0444-0

[12] Jiang, X., Yu, L., Yang, H., Zhou, W. (2020). Shaking table test study of low-buried and unsymmetrical pressure tunnels with rubber shock absorber layer. Geotechnical and Geological Engineering, 1-13. https://doi.org/10.1007/s10706-020-01484-2

[13] Liu, X.R., Li, D.L., Wang, J.B., Wang, Z. (2015). 
Surrounding rock pressure of shallow-buried bilateral bias tunnels under earthquake. Geomechanics and Engineering, 9(4): $427-445$ https://doi.org/10.12989/gae.2015.9.4.427

[14] Lei, M.F., Peng, L.M., Shi, C.H., Xie, Y.J., Tan, L.X. (2015). Upper bound analytical solution for surrounding rock pressure of shallow unsymmetrical loading tunnels. Journal of Central South University, 22(6): 2339-2347. https://doi.org/10.1007/s11771-015-2759-4

[15] Li, L., He, C., Geng, P., Cao, D.J. (2011). Study of shaking table model test for seismic response of portal section of shallow unsymmetrical loading tunnel. Chinese Journal of Rock Mechanics and Engineering, 30(12): 2540-2548.

[16] Gao, F., Sun, C.X., Tan, X.K., Zhu, Y., Li, H. (2015). Shaking table tests for seismic response of tunnels with different depths. Geotechnical, 36(9): 2517-2522, 2531. https://doi.org/10.16285/j.rsm.2015.09.011

[17] Hou, S., Tao, L.J., Li, S.L., Wu, B.L. (2014). Shaking table test for dynamic response in portal section of mountain tunnel with shock absorption layer. World Earthquake Engineering, 30(3): 187-195.
[18] Wang, S.S., Gao, B., Sui, C.Y., Wen, Y.M. (2015). Shaking table vibration damping principle and vibration table test of cross-fault tunnel damping technology. Chinese Journal of Geotechnical Engineering, 37(6): 1086-1092. https://doi.org/10.11779/CJGE201506015

[19] Yan, G.M., Shen, Y.S., Xin, C.L., Gao, B., Zhou, P.F., Zhang, X., Yang, J.Q. (2019). Shaking table test study on the effect of the cavity behind the lining on the seismic response of the tunnel. Chinese Journal of Rock Mechanics and Engineering, 38(12): 2491-2501. https://doi.org/10.13722/j.cnki.jrme.2019.0547

[20] Guan, Z., Zhou, Y., Gou, X., Huang, H., Wu, X. (2019). The seismic responses and seismic properties of large section mountain tunnel based on shaking table tests. Tunnelling and Underground Space Technology, 90: 383-393. https://doi.org/10.1016/j.tust.2019.05.017

[21] Zhuang, H., Hu, Z., Wang, X., Chen, G. (2015). Seismic responses of a large underground structure in liquefied soils by FEM numerical modelling. Bulletin of Earthquake Engineering, 13(12): 3645-3668. https://doi.org/10.1007/s10518-015-9790-6 